\title{
Investigating the multifractality of point precipitation in the Madeira archipelago
}

\author{
M. I. P. de Lima ${ }^{1,2}$ and J. L. M. P. de Lima ${ }^{3,2}$ \\ ${ }^{1}$ Department of Forestry, ESAC/Polytechnic Institute of Coimbra, 3040-316 Coimbra, Portugal \\ ${ }^{2}$ Institute of Marine Research - Coimbra Interdisciplinary Centre, Coimbra, Portugal \\ ${ }^{3}$ Department of Civil Engineering, Faculty of Science and Technology - Campus 2, University of Coimbra, \\ 3030-788 Coimbra, Portugal
}

Received: 1 February 2008 - Revised: 30 March 2009 - Accepted: 30 March 2009 - Published: 15 April 2009

\begin{abstract}
The purpose of this work is to contribute to a better understanding of the variability of precipitation in the Madeira archipelago. This archipelago is located in the Atlantic subtropical belt under the direct influence of the Azores high pressure system. It is formed by Madeira Island $\left(728 \mathrm{~km}^{2}\right)$ and Porto Santo Island $\left(42 \mathrm{~km}^{2}\right)$ and by two other groups of very small inhabited islands. The complex topography of the islands in the Madeira archipelago and their small size play a crucial role in the local precipitation regime, which is marked by high spatial variability.

This paper explores the invariance of properties manifested across scales and determines the fractal and multifractal behaviour observed in the temporal structure of precipitation using daily and 10-min time series from several locations scattered over the main islands. The period covered by the precipitation records is 34 years for the daily data and almost 4 months for the 10-min data. The results show that the temporal structure of precipitation in the Madeira Archipelago exhibits scale-invariant and multifractal properties. The empirical exponent functions describing the scaling statistical properties of the precipitation intensity were characterized using multifractal parameters; these parameters are increasing our awareness of the dynamics of this process in these islands.
\end{abstract}

\section{Introduction}

Precipitation is a highly nonlinear hydrological process that exhibits large variability over a wide range of time and space scales. Because precipitation is the driving agent of many

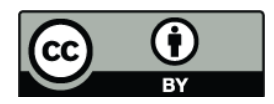

Correspondence to: M. I. P. de Lima (iplima@esac.pt) other processes, its temporal and spatial variability are important issues in many studies and areas of research.

Although the scientific community has dedicated much attention to studying precipitation over the years, it also agrees that more research is still needed to get a better understanding of the variability in this process. There has been a continuous search for methods that can adequately characterize precipitation at different scales and, at the same time, considerable effort has been put into analyzing data from different origins. But as yet these two tasks are incomplete.

Point precipitation data from some areas have not yet been studied satisfactorily: for example, hardly any precipitation studies have focused on the Portuguese and Spanish North Atlantic Islands (i.e. the Azores, Madeira and Canary archipelagos), and even fewer for scales of less than one month. The majority of the few studies that have been conducted were based on large temporal scales (see e.g. GarciaHerrera et al., 2001, 2003; Pereira et al., 2006), and studies undertaken under research projects SIAM (e.g. Miranda et al., 2006) and CLIMAAT (see e.g. de Azevedo et al., 1999). For studies of daily point precipitation see Marzol et al. (2006a, b). Typically, these Atlantic islands have a small area and strong orographic amplitude, and so the spatial variation of climatic conditions is greater there than in flatter regions. The diversity of climate singularities is explained by the elevation, relief and advective processes, which are highly sensitive to small variations in a synoptic situation.

This is what motivated the present study of precipitation in the Madeira archipelago. It explores the invariance of properties manifested across scales and determines the fractal and multifractal behaviour of the temporal structure of precipitation. In this archipelago total annual precipitation varies greatly with geographical location, and this, together with the marked seasonal precipitation regime observed, has strong

Published by Copernicus Publications on behalf of the European Geosciences Union and the American Geophysical Union. 
impacts on society and the environment. The local precipitation regime affects the management of water and bioenvironmental resources, land use, agriculture and tourism, and other factors. It is hoped that the characterization of the dynamics of precipitation with the multifractal approach may improve understanding of the hydrological regime in the islands, and therefore help to define measures supporting the sustainable development of the archipelago. Although the methods used here to studying rain are not novel, we believe that this application has more than a local interest; the large differences in precipitation totals observed across the islands, over distances of only a few kilometres, are uncommon and this study helps clarifying several features of this process under such conditions.

\section{Some aspects of scaling theories}

The invariance of properties maintained across scales can be mathematically investigated using fractal and multifractal theories. These theories have been used to study many different natural processes and systems, including precipitation, and as they are well documented in the literature, we are only reviewing the introductory aspect of these theories and analysis methods. There are presently different formalisms embracing multifractal theory. For a discussion of the relation between the formalism used in this work and other formalisms, which is outside the scope of this work here, see, for example, Marshak et al. (1997); Kantelhardt et al. (2006).

Scale-invariant studies of the temporal structure of precipitation started by using fractal theory (e.g. Hubert and Carbonnel, 1989, 1991; Olsson et al., 1992) and evolved towards the use of multifractal theory (see e.g. Lovejoy and Schertzer, 1990, 1995; Ladoy et al., 1991, 1993; Hubert, 1992, 1995; Tessier et al., 1992, 1993, 1996; Hubert et al., 1993; Olsson and Niemczynowicz, 1994; de Lima and Bogardi, 1995; Olsson, 1995, 1996; Olsson and Niemczynowicz, 1996; Burlando and Rosso, 1996; Harris et al., 1996; Svensson et al., 1996; Bendjoudi et al., 1997; de Lima, 1998, 1999; de Lima and Grasman, 1999; Kiely and Ivanova, 1999; Deidda, 2000; Sivakumar, 2001; de Lima et al., 2002; Veneziano and Furcolo, 2002; Nykanen and Harris, 2003; Veneziano and Langousis, 2005; Kantelhardt et al., 2006; Veneziano et al., 2006; Venugopal et al., 2006; Langousis and Veneziano, 2007; García-Marín et al., 2007; Royer et al., 2008).

Scale-invariance leads to a class of scaling rules (power laws) characterized by scaling exponents. This allows the relationship of variability between different scales to be quantified: statistical properties of scale-invariant systems at different scales (i.e. on large and small scales) are related by a scale-changing operation that involves only scale ratios. Thus scaling theories are developed in non-dimensional frameworks.
Fractal theory (e.g. Mandelbrot, 1977, 1982) deals with simple scaling, which means that such behaviour is determined by one parameter, called fractal dimension (e.g. Mandelbrot, 1977, 1982; Feder, 1988; Falconer, 1990; Hastings and Sugihara, 1993). In defining (fractal) dimension the idea of measurement at scale $\delta$ is fundamental. For each scale $\delta$, irregularities (i.e. details, variability) on smaller scales (i.e. scales of size less than $\delta$ ) are ignored. The notion of dimension is associated with the (scaling) behaviour that is found in the measurements for $\delta \rightarrow 0$.

The number $N_{\delta, A}$ of non-overlapping intervals of side $\delta$ necessary to cover an arbitrary (fractal) set $A$ in a 1dimensional space should satisfy the (power-law) relation

$$
N_{\delta, A} \approx \lambda^{-D_{A}}
$$

meaning that $N_{\delta}$ is proportional to $\delta^{-D}$ in the limit $\delta \rightarrow 0$. In Eq. (1) parameter $D_{A}$ is the (fractal) dimension of the set $A$. This parameter can be obtained by the box-counting method (see e.g. Feder, 1988; Falconer, 1990; Hastings and Sugihara, 1993). In practical applications of this method, the $D$-dimensional space of the observations is covered with gradually-decreasing (it is common that the size is decreased gradually by a factor of 2), non-overlapping boxes of side $\delta$. For every grid-size, the number of boxes that contain at least one point of the set being analysed are "counted". If the set exhibits scale-invariance, plots of $\log \left(N_{\delta, A}\right)$ against $\log (\delta)$ should yield a linear relation indicating the scaling in the form of the power law (Eq. 1). The fractal dimension $D_{A}$ can be estimated from the slope of the regression line fitted to the data.

For rainfall, the geometric structure that is the "support" of the process can be regarded as a fractal object embedded in the 1-dimensional space of time and is defined as the set of rain periods observed in a particular location. Its fractal dimension, $D$, is between 0 and 1 . Thus, this approach deals only with the binary question of occurrence and nonoccurrence of the precipitation process; in practice this definition is associated with an intensity threshold. Very roughly, the dimension of a set tells how densely the set occupies the metric space in which it lies (e.g. Falconer, 1990).

Multifractal theory (e.g. Mandelbrot, 1972, 1974; Hentschel and Procaccia, 1983; Grassberger, 1983; Schertzer and Lovejoy, 1983) deals instead with multiscaling. It can handle the different intensity levels of processes, namely precipitation. Multifractal behaviour is determined not by one, but by an infinity of scaling exponents.

The multifractal temporal structure of the precipitation process can be investigated by studying the (multiple) scaling of the statistical moments of the precipitation intensity (Schertzer and Lovejoy, 1987). The scaling of the moments of the precipitation intensity is described by the exponent function $K(q)$. The notion of moment can be generalized to any real value $q$. The moments scaling function $K(q)$ satisfies

$<R_{\lambda}^{q}>\approx \lambda^{K(q)}$ 
where $\left\langle R_{\lambda}^{q}>\right.$ is the (ensemble) average qth moment of the (non-dimensional) precipitation intensity $R_{\lambda}$ on a scale specified by $\lambda$. Parameter $\lambda$ is introduced as the scale ratio $\lambda=L / \delta$ used here instead of the length $\delta$ of the scale of homogeneity, defined for a set of size $L$ embedded in a 1-dimensional space. To non-dimensionalize the precipitation intensity $R_{\lambda}$, the intensity on a time scale of resolution $\lambda$ can be divided by the ensemble average intensity of the process. The scaling of the moments can be tested with $\log -\log$ plots of $\left\langle R_{\lambda}^{q}>\right.$ on different scales, against the scale ratio $\lambda$. The empirical $K(q)$ functions can be obtained using the Trace Moment method; for a detailed discussion on this methodology see e.g. Schertzer and Lovejoy (1987).

Another equivalent way to investigate the multifractal temporal structure of precipitation uses the probability distributions of the precipitation intensity. The precipitation intensity threshold level is evaluated here with the order of singularity $\gamma$ of the intensities $R_{\lambda} \sim \lambda^{\gamma}$ (e.g. Frisch and Parisi, 1985; Halsey et al., 1986; Schertzer and Lovejoy, 1987). Please note the definition just given for singularity, since this term bears several meanings in the literature (see e.g. Marshak et al., 1997). The scaling of the probability distributions of the precipitation intensity (e.g. Schertzer and Lovejoy, 1987) is given by the exponent codimension function $c(\gamma)$ :

$\operatorname{Pr}\left(R_{\lambda} \geq \lambda^{\gamma}\right) \approx \lambda^{-c(\gamma)}$

This statistical characterization of multifractals arises directly from multiplicative cascade processes (see e.g. Schertzer and Lovejoy, 1987, 1988). In this case the scaling behaviour can be tested with log-log plots of the probability of exceeding different levels of the precipitation intensity $R_{\lambda}$, observed on scales of different levels of resolution $\lambda$, against the scale ratio $\lambda$ (e.g. Lavallée et al., 1991). The empirical codimension function $c(\gamma)$ can be estimated using the Probability Distribution/Multiple Scaling method (see e.g. Lovejoy and Schertzer, 1990; Lavallée et al., 1991).

The two multifractal scaling exponent functions $c(\gamma)$ and $K(q)$ are related through the formulas

$$
K(q)=\max _{\gamma}\{q \gamma-c(\gamma)\} \text { and } c(\gamma)=\max _{q}\{\gamma q-K(q)\}
$$

which are Legendre transform pairs that establish a one-toone correspondence between orders of singularity $\gamma$ and statistical moments $q$ (e.g. Frisch and Parisi, 1985).

In multifractals, there is only a convexity constraint on the scaling exponent functions $c(\gamma)$ and $K(q)$. Functional forms for these scaling exponents are proposed by the Universal Multifractal Model (Schertzer and Lovejoy, 1987) that are theoretically derived on the basis of stable, attractive multifractal processes. This model has a multiplicative cascade structure and is based on Lévy stochastic variables. For the moments scaling function of conserved processes it is:

$$
K(q)=\frac{C_{1}}{\alpha-1}\left(q^{\alpha}-q\right)
$$

for moments $q$ in the nonlinear regime, $q>0$ and $\alpha \neq 1$ (Schertzer and Lovejoy, 1987). For universal multifractals, the (dual) expression for the function $c(\gamma)$, in Eq. (3), is obtained with the help of Legendre transforms.

In Eq. (5) the Lévy index $\alpha$, also called the degree of multifractality, is defined in the interval $[0,2]$ although for the case $\alpha=1$ an expression different from Eq. (5) is used to describe the empirical $K(q)$ function. Parameter $C_{1}$ describes the sparseness or non-homogeneity of the mean of the process: it is the codimension of the mean singularity. The multifractal parameters $C_{1}$ and $\alpha$ can be determined, for example, using the Double Trace Moment (DTM) method (see e.g. Lovejoy and Schertzer, 1991).

For non-conserved processes a third parameter, $H$, is introduced in the functional forms of the scaling functions, $K(q)$ and $c(\gamma)$, which characterizes the deviation from conservation (that is: $\left\langle R_{\lambda}\right\rangle=\lambda^{-H}$ ); for conserved processes is $H=0$. This parameter is sometimes known theoretically for different processes, although usually it must be determined experimentally; for estimation methods of parameter $H$ see e.g. Tessier et al. (1993) and Lovejoy and Schertzer (1995). Interpretations for the meaning of $H>0$ and $H<0$ are given in these works together with a discussion of implications for characterizing multifractal processes. For a discussion of statistical stationarity and stochastic continuity see e.g. Davis et al. (1994, 1996) and Kantelhardt (2008).

Discussions of the relation between the universal multifractal parameters and parameters used in other multifractal formalisms, and of the Universal Multifractal Model in comparison to multifractal cascade models that were developed for applications in strange attractors and chaos are given in e.g. Kantelhardt et al. (2006), Lovejoy and Schertzer (2007) and Kantelhardt (2008).

\section{The precipitation data and the study area}

\subsection{Brief description of the study area}

The precipitation data used in this work were recorded in several meteorological stations located in the Madeira Archipelago (Portugal). This archipelago is situated in the North Atlantic Ocean, about $900 \mathrm{~km}$ from Mainland Europe (see Fig. 1). It is formed by Madeira Island $\left(728 \mathrm{~km}^{2}\right)$ and Porto Santo Island $\left(42 \mathrm{~km}^{2}\right)$ and by two other groups of very small inhabited islands. Porto Santo Island is $40 \mathrm{~km}$ northeast of the main island.

The islands' most frequent circulation pattern is controlled by the Azores high pressure system with northerly flow, and the second most important is the westerly flow, due to perturbations associated with the normal track of Atlantic depressions. The climate in the archipelago is mild all year round, though there are exceptions at the highest altitudes, where the temperature is lower. Mean annual air temperature is between $8^{\circ} \mathrm{C}$ in the highest altitudes and $18-19^{\circ} \mathrm{C}$ in the coastal regions. 


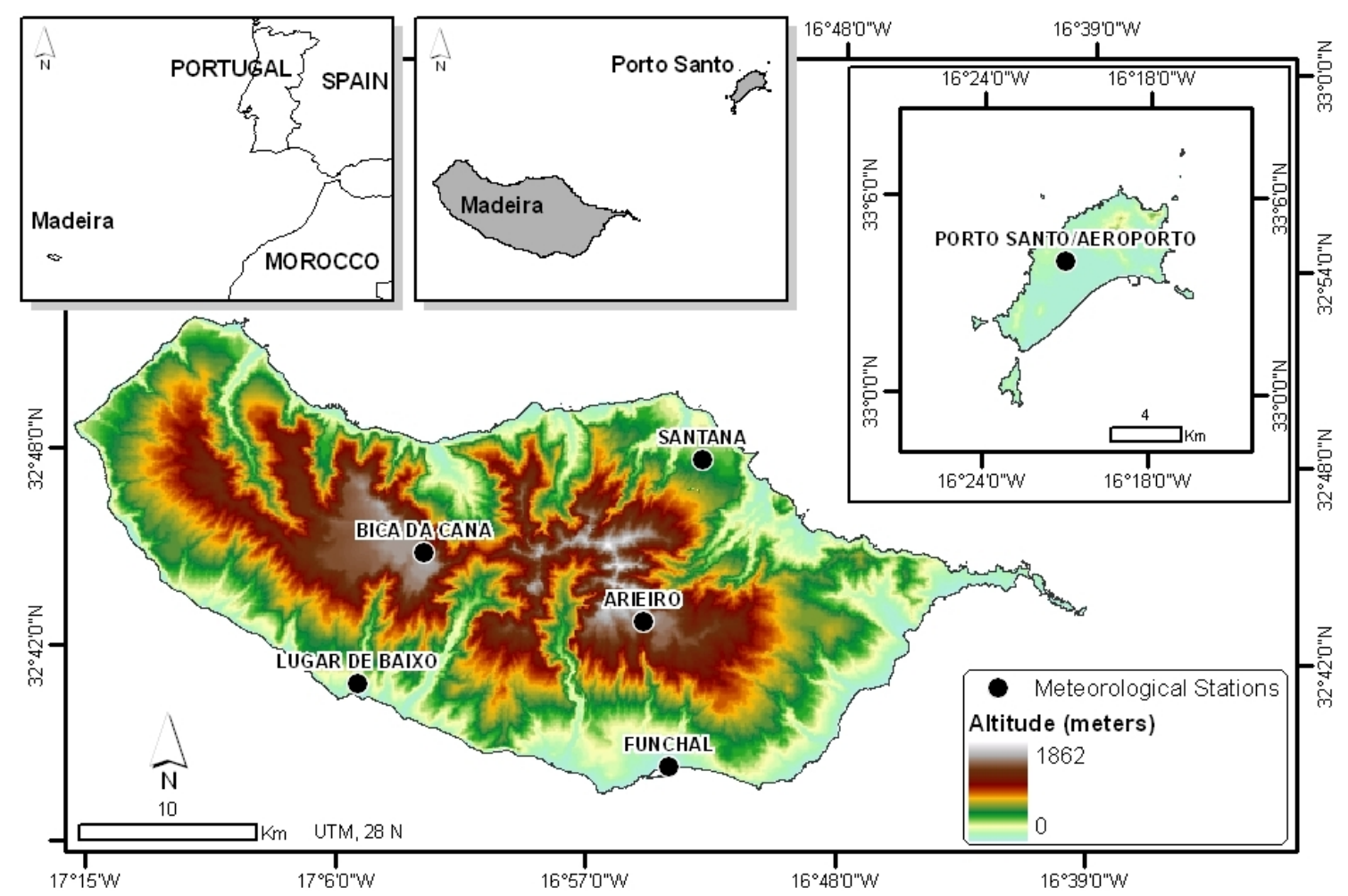

Fig. 1. Altimetry map of the Madeira archipelago and location of the 6 precipitation measuring sites used in this study.

The low pressure systems that cross the Atlantic in the winter and move down to Madeira's latitude, or the ones formed between the archipelago and mainland Portugal, can result in high precipitation. The northerly flows (which are associated with the east branch of the Azores High) are predominant in summer. However, in the Madeira archipelago, the local scale climate is influenced by the regional scale climate and by the orography and orientation of air mass movement over the islands. The relief of Madeira Island is dominated by a central peak $(1862 \mathrm{~m})$ which divides the island into a northern and a southern part. The highest point on Porto Santo Island is $517 \mathrm{~m}$.

\subsection{Precipitation time series}

The data analysed in this work are daily and 10-min precipitation time series collected by the Portuguese Institute of Meteorology (IM) in the Madeira Archipelago. The distribution of measuring sites with available long daily records is sparse in the archipelago, and some sectors of the islands are not covered (e.g. the western sector of Madeira Island). Moreover, the time span of the records varies from station to station. Although several automatic stations are presently being operated on the islands, their continuous records of precipitation are quite short and there are a lot of gaps in the time series records available. For this study we selected a 3.8 months long time series without missing data; the data were recorded in the meteorological station of Funchal/Observatório, from November 2001 to February 2003. The precipitation in this period was $555 \mathrm{~mm}$.

The selection of the daily data sets used in this work aimed at analysing data from various locations in the islands over a common period; this was considered crucial to understanding better the spatial variation of rainfall in the archipelago. A compromise was to select daily precipitation data recorded at 5 locations scattered over Madeira Island and at one location on Porto Santo Island, for the period 1961-1994 (see Table 1). A daily time series from Funchal for the period 1961-2005 is also used; mean annual precipitation in this period was $618.7 \mathrm{~mm}$. Figure 1 shows the location of the measuring sites and also the altimetry of the islands. The precipitation data do not provide uniform spatial coverage of the islands; in Madeira the measuring sites are located on the northern and southern coasts, and in the island's central highlands.

\subsection{Annual and seasonal precipitation regimes}

Annual precipitation differs not only between the two main islands of the archipelago but also within Madeira Island itself. This was not confirmed for Porto Santo Island since this study only uses one data set from this island. Nevertheless, the small size of this island and a considerable (relatively) smoother relief than in the Madeira Island allow us 
Table 1. Daily precipitation series. The statistics are for the period 1961-1994. Parameter $c v$ is the coefficient of variation, defined by the ratio between the standard deviation and the mean.

\begin{tabular}{llllrrr}
\hline Code & Station name & Island & $\begin{array}{l}\text { Location in the } \\
\text { island }\end{array}$ & $\begin{array}{r}\text { Altitude } \\
(\mathrm{m})\end{array}$ & $\begin{array}{r}\text { Mean annual } \\
\text { prec. }(\mathrm{mm})\end{array}$ & $c v$ annual \\
\hline 524 & Porto Santo/Aeroporto & Porto Santo & Central & 78.0 & 379.4 & 0.27 \\
522 & Funchal/Observatório & & Southern sector & 49.3 & 631.9 & 0.30 \\
385 & Lugar de Baixo & & 40.1 & 638.8 & 0.29 \\
365 & Santana & \multirow{2}{*}{ Madeira } & Northern sector & 400.5 & 1458.0 & 0.18 \\
370 & Bica da Cana & & Central highlands & 1571.0 & 2906.3 & 0.25 \\
373 & Arieiro & & & 1582.5 & 2923.5 & 0.21 \\
\hline
\end{tabular}

to anticipate much smaller spatial precipitation variability than in the main island. In the Madeira Island there are marked differences between the northern and southern regions, and the more inland regions (see Table 1). In the period 1961-1994 the wettest site was Arieiro, in the central part of Madeira Island, with an average yearly precipitation of $2924 \mathrm{~mm}$; the driest location was in Porto Santo Island, with $379 \mathrm{~mm}$ per year. It should be stressed that the mean annual precipitation in Madeira more than quadruplicates over distances of roughly $10 \mathrm{~km}$ (e.g. from Funchal, in the southern sector, to Arieiro, in the central highlands, where the multiplying factor is 4.6).

Although total precipitation strongly depends on the location of the station, its monthly distribution is very similar. The precipitation regime in the islands shows a strong seasonality (Fig. 2): maximum monthly rainfall occurs during autumn and winter and there are frequently very dry or even rainless months from April to September. Although there are strong variations between the different locations in terms of mean monthly precipitation (Fig. 2a), on average the monthly percentages of the corresponding annual precipitation for the different stations are almost identical (Fig. 2b). For the six stations studied, Fig. $2 \mathrm{~b}$ shows the average percentage contribution of the monthly precipitation to the annual precipitation. From 1961 to 1994 the wettest and driest months, on average, were December and July, respectively. In this period, approximately $44 \%$ of the annual precipitation felt between November and January, which was the wettest trimester. The driest trimester was June to August, with less than 5\% of the annual precipitation.

\section{Scaling and multifractal analysis of precipitation data}

This section presents results of the characterization of the fractal and multifractal behaviour of temporal precipitation in the Madeira archipelago, studied with both daily and 10min time series (see Sect. 3). a)

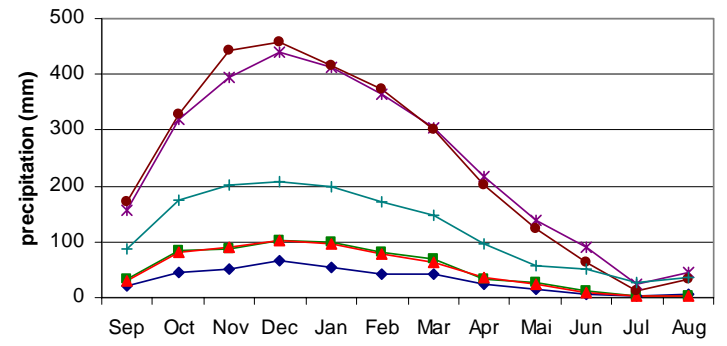

b)

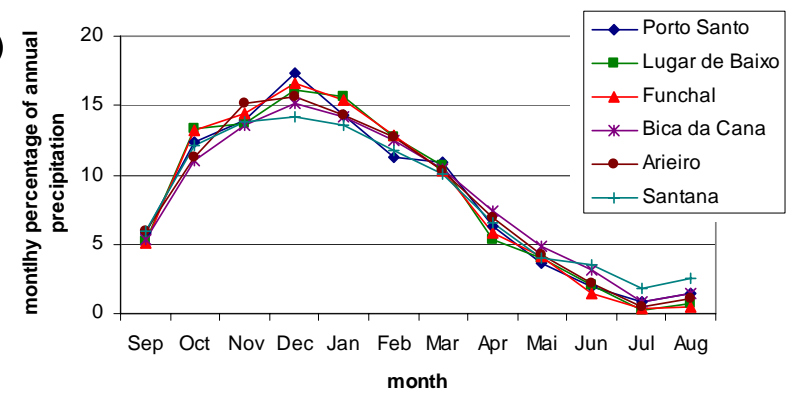

Fig. 2. Average monthly distribution of the annual precipitation, for six locations in the Madeira archipelago, for the period 1961-1994: (a) in depth (mm); (b) as a percentage of annual precipitation.

\subsection{Distribution of rainfall occurrences characterized by fractal theory}

To test the scale-invariant temporal structure of precipitation we first applied the box-counting method (see Sect. 2). No thresholding was considered to convert the time series into sets of points. However, the minimum amount of precipitation recorded by conventional gauges is $0.1 \mathrm{~mm}$. The boxcounting plots obtained for Funchal are shown in Fig. 3a using daily precipitation data for the period 1961-2005 and in Fig. $3 \mathrm{~b}$ using the 10 -min time series for the 3.8 months period, November 2001-February 2002. Analysis of the boxcounting plots for the daily data shows that precipitation occurrences on scales from 1 day to about 16 days are characterized by a fractal dimension 0.56 (see Eq. 1); using the 10-min data, precipitation occurrences on the range of scales from $10 \mathrm{~min}$ to roughly 3.6 days are characterized by a fractal 
Table 2. Summary of results of the fractal (box-counting) analysis of precipitation data from the Madeira archipelago: scaling range, fractal dimension, $D$, and corresponding standard error.

\begin{tabular}{lcccll}
\hline Station & Scaling range & $D$ & $\begin{array}{l}\text { Stand. } \\
\text { error }\end{array}$ & Island & $\begin{array}{l}\text { Location in } \\
\text { the island }\end{array}$ \\
\hline For daily data, 1961-1994: & & & & \\
\hline Porto Santo/Aeroporto & 1 day-16 days & 0.613 & 0.038 & Porto Santo & Central \\
Funchal/Observatório & 1 day-16 days & 0.565 & 0.022 & & Southern sector \\
Lugar de Baixo & 1 day-16 days & 0.534 & 0.012 & Madeira & Northern sector \\
Santana & 1 day-16 days & 0.714 & 0.033 & Central highlands \\
Bica da Cana & 1 day-16 days & 0.720 & 0.022 & & \\
Arieiro & 1 day-16 days & 0.757 & 0.019 & & Southern sector \\
\hline For daily data, 1961-2005: & & & & Madeira \\
\hline Funchal/Observatório & 1 day-16 days & 0.562 & 0.020 & & Southern sector \\
\hline For 10 min data, November 2001-February 2002: & & & \\
\hline Funchal/Obervatório & 10 min-3.6 days & 0.562 & 0.005 & Madeira & \\
\hline
\end{tabular}
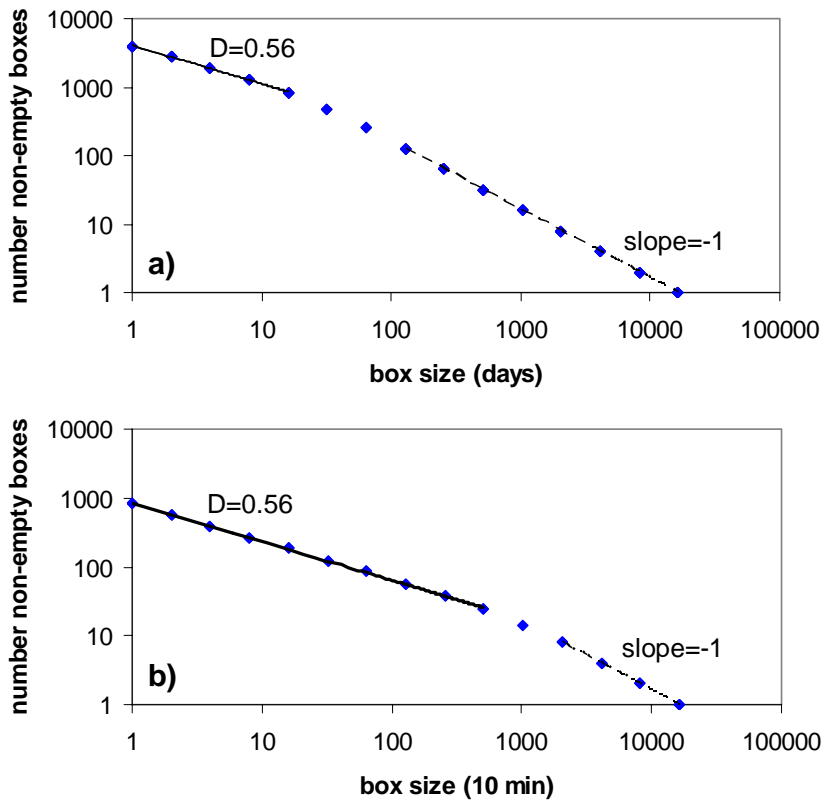

Fig. 3. Box-counting plots obtained with precipitation from Funchal, Madeira: (a) for daily time series from 1961 to 2005; (b) for 10-min time series, from November 2001 to February 2002. Straight lines were fitted to the data: between 1 and 16 days, for the daily data plot; and between $10 \mathrm{~min}$ and roughly 3.6 days, for the 10-min data plot. The regression lines are used to estimate the corresponding fractal dimensions $D$.

dimension 0.56. These values are estimated from the absolute values of the slopes of the regression (heavy) lines fitted to the left-hand side sections of the plots. The smaller upper limit of the scaling range observed for the 10-min data is expected to be influenced by the smaller size of this sample in comparison with the daily data sample. Moreover, the 10-min sample covers a wet period, which leads to the observation of "saturation" (i.e. trivially the slope is -1 ) for scales larger than roughly one week. Also for the daily data plots the analyses of larger time scales are affected by "saturation", which is a practical problem of applying the boxcounting method to precipitation occurrences. Nevertheless, results indicate a scaling behaviour spanning a wide range of time scales, from 10 min up to about 2 weeks.

The results of the box-counting analyses for the remaining stations are given in Table 2; they show that the scaling range is the same for all locations. The fractal dimensions given in Table 2 provide an ensemble characterization of precipitation occurrences over time at these locations. They reflect that in the northern sector and in the central highlands of the Madeira Island the fraction of rainfall events is larger (i.e. the fractal dimension is larger) than in the southern sector of the Island, an effect that is related to the effect of orography on the rain distribution in time and space. Orographic precipitation occurs on the windward side of mountains and is caused by the rising air motion of a large-scale flow of moist air across the mountain ridge, resulting in adiabatic cooling and condensation. Consequently, the leeward side is drier. Moisture is removed by orographic lift, leaving drier air on the descending (generally warming), leeward side. This phenomenon results in substantial local gradients of average rainfall. For the Madeira Island (see Table 1) the windward side corresponds to the northern sector and the leeside to the southern sector.

The scaling range and the fractal dimensions reported in various studies of point precipitation suggest that they depend on geographical location, while expressing different 


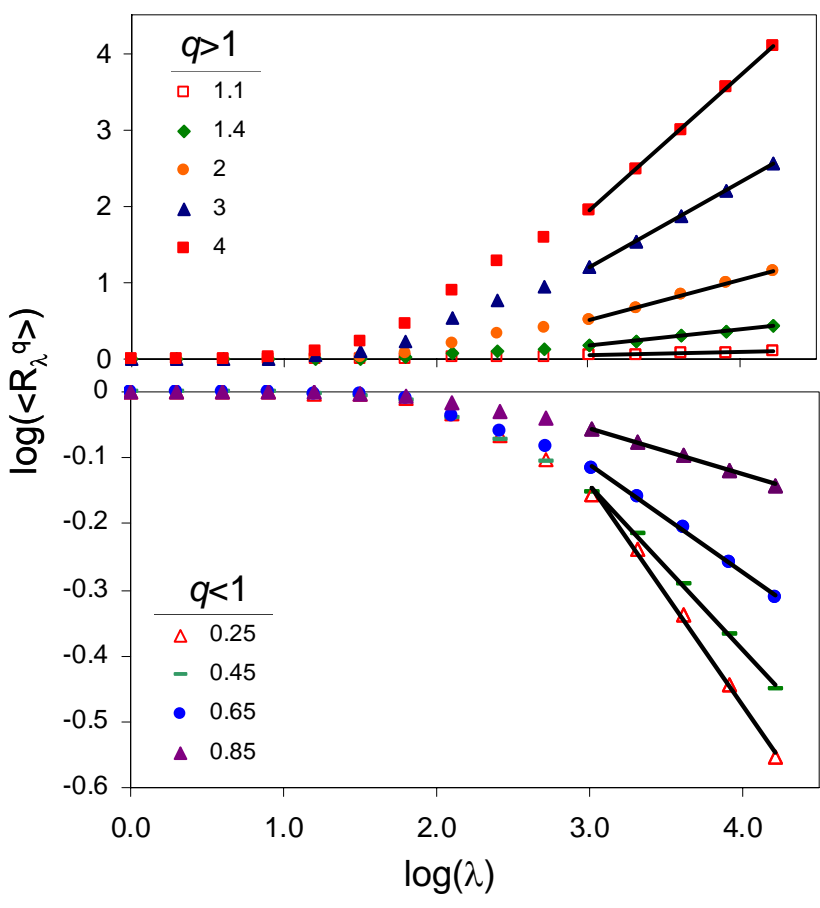

Fig. 4. Log-log plot of the average qth moments of the precipitation intensity $R_{\lambda}$ on scales between 1 day and 16384 days, against the scale ratio $\lambda$ : (top) for moments greater than 1; and (bottom) for moments smaller than 1. Data are daily precipitation from Funchal/Observatório, for the period 1961-2005. Straight lines were fitted to the data between 1 and 16 days.

distributions of precipitation in time. A scaling range similar to what was found for the daily data used in this work, between 1 and 16 days, was observed, for example, by Tessier et al. (1996) and Royer et al. (2008) when analysing rainfall daily time series over France. Studies focussing on data of other origins and record lengths report different results for the scaling range; see e.g. Fraedrich and Larnder (1993), Hubert (1995), Olsson (1995), de Lima (1999), Lovejoy et al. (2003), García-Marín et al. (2007). There are also studies reporting scaling ranges for small samples and even for storm events. Usually such studies identify much narrower scaling ranges than the ones reported by studies that analyse large samples (which aim at characterizing the ensemble). Analyses of storm event samples yield upper limits for the scaling range that are typically of the order of a few hours (even less than one hour), scales comparable to the mean storm duration (see e.g. Olsson et al., 1992; Onof et al., 1996; Harris et al., 1996; Purdy et al., 2001; Venugopal et al., 2006). Also the precipitation statistics are, in this case, for particular events.

\subsection{Multifractal scaling range}

To test the temporal multifractal character of precipitation, the scaling of the moments of the precipitation intensity were investigated. For the daily data from Funchal/Observatório

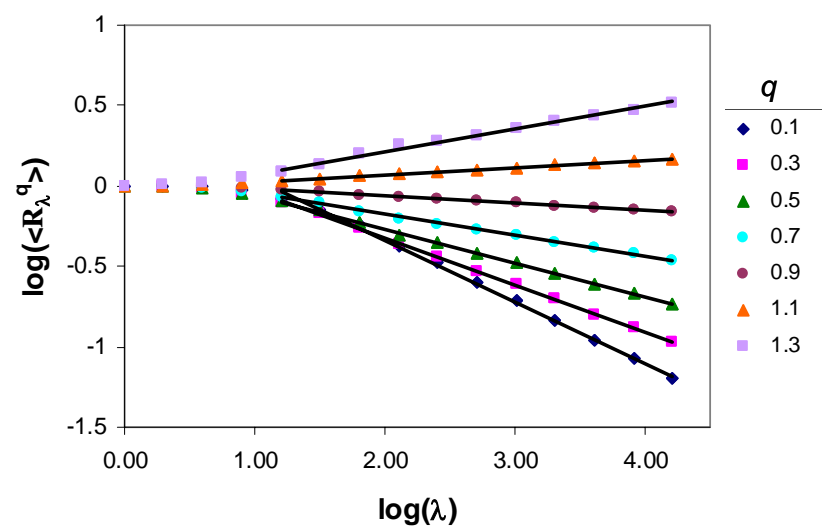

Fig. 5. Log-log plot of the average qth moments of the precipitation intensity $R_{\lambda}$ on scales between $10 \mathrm{~min}$ and 3.8 months, against the scale ratio $\lambda$. The moments $q$ plotted are indicated in the legend. Data are 10-min precipitation from Funchal/Observatório, for the period November 2001-February 2002. Straight lines were fitted to the data between $10 \mathrm{~min}$ and 7.1 days.

(1961-2005), Fig. 4 shows the log-log plot of the average qth moments of the precipitation intensity $R_{\lambda}$ on time scales from 1 day ( $\lambda=16384)$ up to 16384 days (44.9 years, $\lambda=1)$, against the scale ratio $\lambda$. Figure 4(top) shows moments larger than 1 and Fig. 4(bottom) moments smaller than 1. The moments $q$ plotted in Fig. 4 are indicated in the legend. The scaling range seems to extend from 1 day to about 16 days, similarly to the box-counting result.

For the 10-min data, Fig. 5 shows the moments' scaling plot of the precipitation intensity $R_{\lambda}$ on time scales from $10 \mathrm{~min}(\lambda=16384)$ up to roughly 3.8 months $(163840 \mathrm{~min}$, $\lambda=1$ ), against the scale ratio $\lambda$. The moments $q$ plotted in Fig. 5 are again indicated in the legend. In this case, the scaling range seems to extend from 10 min to 7.1 days (see regression line fits in Fig. 5). Attention is drawn to the uncertainty in the estimation of large moments, which can be attributed to the small length of the time series. Even so, results suggest that the multifractal temporal behaviour of precipitation is valid down to scales of at least $10 \mathrm{~min}$, thus confirming the scaling range found in the mono-fractal analysis (see Fig. 3b). The multifractal structure observed down to such small scales needs further investigation using more data (i.e. longer series, data from more locations), which were not available for this study.

\subsection{Multifractality of precipitation}

The empirical functions $K(q)$, in Eq. (2), that describe the scaling of the moments of the precipitation intensity from 1 day up to 16 days are plotted in Fig. 6 (left): the functions were determined using the Trace Moment method (see Sect. 2) using daily data. For the daily data from Funchal, the magnitude of the standard error associated to the estimate of $K(q)$ for the different moments $q$ are in the range 

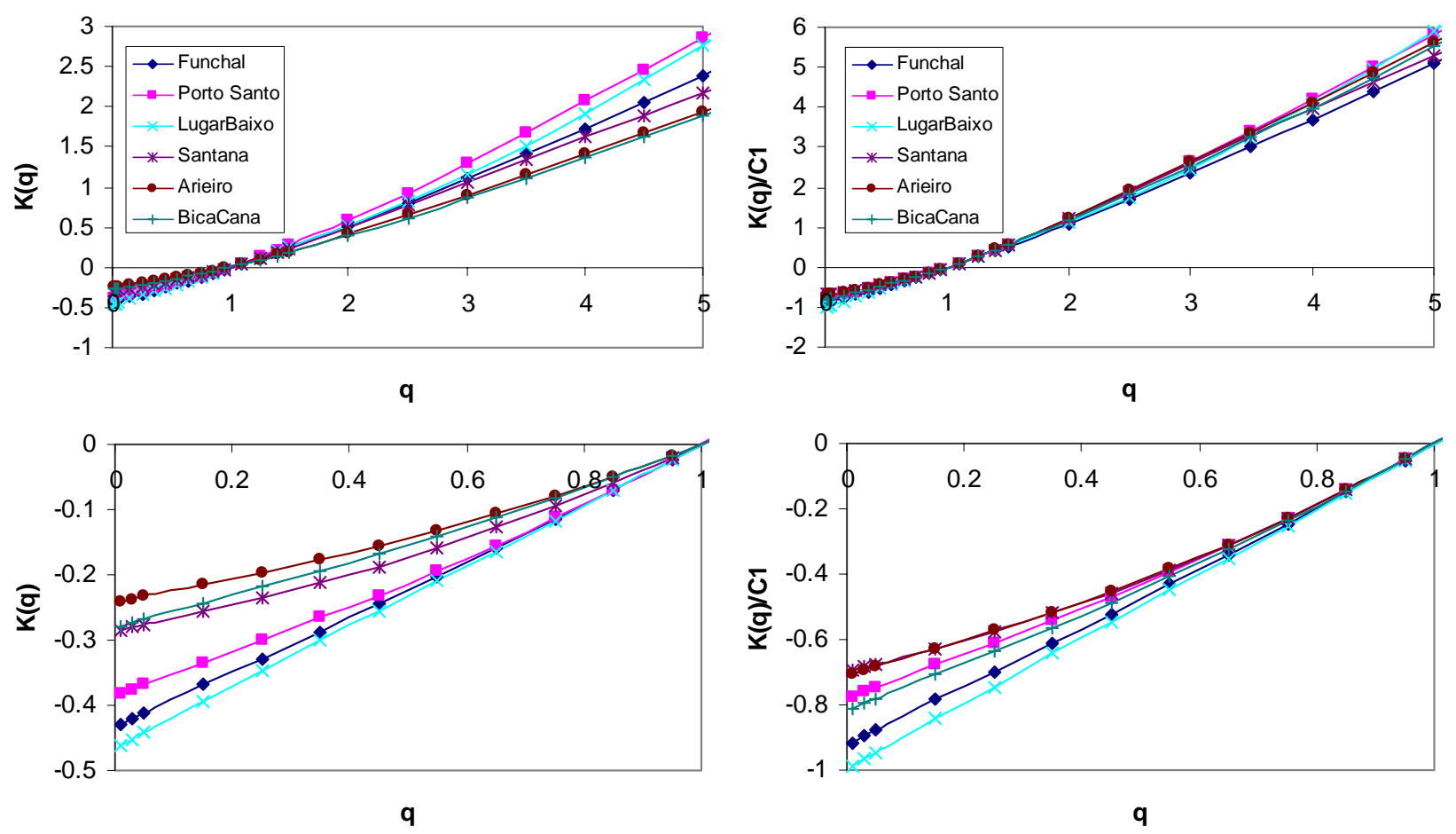

Fig. 6. Empirical moments scaling function determined using daily precipitation data from the Madeira archipelago, for the period 19611994; the scaling behaviour is valid for the range of scales from 1 day to 16 days. The left-hand side plots show the usual $K(q)$ functions and the right-hand side plots show versions of the moments scaling functions rescaled with respect to the corresponding multifractal parameter, $C_{1}$. The plots at the bottom show details of the empirical scaling functions for moments smaller than 1.

from 0.001 and 0.020 . For this data set the highest values of the standard error are observed for the smallest moments $q$ investigated (see Fig. 6) and the lowest values are associated to the moments around $q=1$ (but different from 1); standard errors larger than 0.01 are associated to estimates of the scaling function for $q<0.3$ and $q>3$. For the other data sets the behaviour is similar.

Figure 6 shows that here the empirical functions $K(q)$ consist of both nonlinear and linear sections, and this statistical behaviour is discussed below. The various statistical parameters estimated in the analysis are presented in Table 3 for the different data sets. For the large rain rate part of the statistics, the empirical $K(q)$ functions are linear for moments $q$ exceeding a critical value $q_{\text {crit }}$. Such a discontinuity in the first or second derivative of $K(q)$ arises either because of divergence of moments at $q_{\text {crit }}$ (called $q_{D}$ in this first order case) or it is simply due to the inadequate sample size (at $q_{s}$, in the second order case), so that all moments larger than $q_{s}$ are determined by the largest value in the sample (see e.g. Schertzer and Lovejoy, 1991). The corresponding largest singularity present in the sample can be determined from $\gamma_{\max }=\max \left(K^{\prime}(q)\right)$; this singularity $\gamma_{\max }$ dominates the statistics. The intercept of the corresponding linear section in the $K(q)$ function is an estimate of $c\left(\gamma_{\max }\right)$. A complete and systematic characterization of the extremes is best undertaken with the help of the complementary scaling func- tion $c(\gamma)$ in Eq. (2), i.e. by conducting a systematic study of the probability distributions, but this is beyond the scope of this work. Multifractals contain singularities of extreme orders which are related to algebraic decays of the extreme events (i.e. algebraic tails of the probability distributions); these are associated with processes' "violent" character (see e.g. Hubert et al., 1993; Olsson, 1995; de Lima, 1998; Purdy et al., 2001; de Lima et al., 2002; Douglas and Barros, 2003; García-Marín et al., 2007).

In terms of $K(q)$ and $c(\gamma)$, the low rain rates are characterized by $K(0)=-C_{s}=c\left(\gamma_{\min }\right)$, where $C_{s}$ is the codimension of the support (i.e. the regions with $R>0$; the corresponding fractal dimension of the support is $D=1-C_{S}$ ), and $\gamma_{\min }=\min \left(K^{\prime}(q)\right)$, which is the lowest singularity in the data. For the cases analyzed in this study, where $C_{s}>0$, then the low $K(q)$ is linear for $q<q_{\min }$ so that the moments $q<q_{\min }$ are determined by the lowest nonzero rain rates. The various critical exponents are listed in Table 3. The estimates of the fractal dimension obtained using the box-counting method, listed in Table 2, are consistent with the estimates of the (fractal) codimension $C_{s}$ obtained via the analysis of the statistical moments of the rain rates. 
Table 3. Summary of estimates of the critical statistical exponents that describe the scaling of the precipitation intensity determined from daily data. The symbols are defined earlier in the text. Parameters $\alpha$ and $C_{1}$ were estimated using two methods. Besides being estimated using the DTM method, the $\alpha$ values were also estimated using the radius of curvature of the empirical $K(q)$ functions at $q=1$ : $R_{K}(q=1)=\left[\frac{\left(1+K^{\prime}(q)\right)^{3 / 2}}{K^{\prime \prime}(q)}\right]_{q=1}=\frac{\left(1+C_{1}\right)^{3 / 2}}{C_{1} \alpha}$; we furthermore estimated $C_{1}=K^{\prime}(1)$. Scaling range is from 1 day to 16 days.

\begin{tabular}{|c|c|c|c|c|c|c|c|c|c|}
\hline \multirow[t]{2}{*}{ Station } & \multirow[t]{2}{*}{$\gamma_{\min }$} & \multirow[t]{2}{*}{$\gamma_{\max }$} & \multirow[t]{2}{*}{$\gamma_{\max } / C_{1}$} & \multirow[t]{2}{*}{$c\left(\gamma_{\min }\right)$} & \multirow[t]{2}{*}{$c\left(\gamma_{\max }\right)$} & \multicolumn{2}{|c|}{$C_{1}$} & \multicolumn{2}{|r|}{$\alpha$} \\
\hline & & & & & & $\begin{array}{c}\text { DTM } \\
\text { estimate }\end{array}$ & $\begin{array}{c}\text { from empirical } \\
\qquad K(q)\end{array}$ & $\begin{array}{c}\text { DTM } \\
\text { estimate }\end{array}$ & $\begin{array}{c}\text { from empirical } \\
\qquad K(q)\end{array}$ \\
\hline Porto Santo/Aeroporto & 0.35 & 0.80 & 1.62 & 0.39 & 0.55 & $0.49 \pm 0.01$ & 0.49 & $0.55 \pm 0.03$ & 0.39 \\
\hline Funchal/Observatório & 0.45 & 0.68 & 1.44 & 0.43 & 0.48 & $0.47 \pm 0.01$ & 0.47 & $0.48 \pm 0.03$ & 0.18 \\
\hline Lugar de Baixo & 0.50 & 0.90 & 1.92 & 0.47 & 0.50 & $0.47 \pm 0.01$ & 0.48 & $0.50 \pm 0.04$ & 0.18 \\
\hline Santana & 0.18 & 0.52 & 1.27 & 0.29 & 0.63 & $0.41 \pm 0.01$ & 0.41 & $0.63 \pm 0.02$ & 0.38 \\
\hline Bica da Cana & 0.25 & 0.54 & 1.58 & 0.28 & 0.63 & $0.34 \pm 0.01$ & 0.34 & $0.63 \pm 0.02$ & 0.30 \\
\hline Arieiro & 0.20 & 0.52 & 1.53 & 0.24 & 0.71 & $0.34 \pm 0.01$ & 0.35 & $0.71 \pm 0.02$ & 0.38 \\
\hline
\end{tabular}

The function $K(q)$ for the values near the mean $(q=1)$ can be characterized using $C_{1}=K^{\prime}(1)$ and the radius of curvature $R_{K}$ at $q=1$ by the parameter $\alpha$ via the relation

$R_{K}(q=1)=\left[\frac{\left(1+K^{\prime}(q)\right)^{3 / 2}}{K^{\prime \prime}(q)}\right]_{q=1}=\frac{\left(1+C_{1}\right)^{3 / 2}}{C_{1} \alpha}$.

This characterization of the curvature by $\alpha$ has the advantage that in the case of universal multifractals this single parameter, $\alpha$, characterizes the entire $K(q)$ function.

For the data sets analysed there is a discrepancy between the estimates of parameter $\alpha$ using the DTM method (see Sect. 2) and the method described above (i.e. using Eq. 6), in that the DTM estimates yielded larger values of $\alpha$. For $C_{1}$, the estimates given by the two methodologies are very close. A summary of estimates of statistical exponents is presented in Table 3.

Results show that the degree of multifractality of rain, as expressed by parameter $\alpha$, is lower for the drier southern sector of the Madeira Island and for Porto Santo Island. The data from the highlands in central Madeira Island exhibit the lower parameters $C_{1}$ which indicates the smaller intermittency and sparseness of the mean of the rain process at these locations.

The estimate of $\gamma_{\min }=0.50$ for Lugar de Baixo (Table 3), which is greater than $C_{1}$, is interpreted as resulting from uncertainty in the estimation of statistical parameters; for this data it is also the codimension of the support $C_{s}$ equal to $C_{1}$ (the codimension of the singularity of the mean). For the other cases in Table 3 it is $C_{1}>C_{s}$, as expected.

Parameter $H$ can be estimated using the relation $H=(\beta-1+K(2)) / 2$, where $\beta$ is the spectral exponent. The average value estimated from the 6 individual daily series is $H=-0.134 \pm 0.018$, for values of $K(2)$ estimated from the empirical functions. The error estimate is the dispersion of the corresponding parameters estimated from the individual series. The values of $H$ found in this work are within the range of values already reported in the literature for other rain gauge precipitation studies. Depending on geographical location and characteristics of the time series, both positive and negative values of $H$, as well as values roughly equal to zero, have been determined from data analyses; e.g. Royer et al. (2008) for precipitation in France reported $-0.2<H<0.2$.

To better compare the scaling behaviour observed for the data recorded at the different locations, on the right-hand side of Fig. 6 the same empirical scaling functions that are on the left-hand side are re-plotted, this time after rescaling the functions with respect to $C_{1}$. These plots show that the behaviour of the $K(q)$ functions around the mean (i.e. $q=1$ ), at the different locations, is very similar. Nevertheless, for the low intensities, which are highlighted by the low moments, the behaviours are quite different, leading to differences in the geometric support of the process as expressed by the different fractal dimensions $D$ (see Table 2). The results indicate the more persistent character of precipitation in the highlands and windward side of the Madeira Island. There are also differences in the high intensities, which are now highlighted by the high moments, with Porto Santo and Lugar de Baixo exhibiting the largest (relative) singularities: it is $\gamma_{\max }=\max \left(K^{\prime}(q)\right)$. This suggests a more violent behaviour of precipitation recorded in these locations. Note that the Porto Santo/Aeroporto data set is the only sample analyzed from the island of Porto Santo, and that it is the driest location studied in the archipelago.

Results show that for the Madeira data, the low rain rate cut-off is in certain cases nearly equal to the mean (climatological) rain rate, as can be inferred from the fact that $c\left(\gamma_{\min }\right)$ is almost as large as $C_{1}$ (see Table 3 ). For the daily data this low rain rate cut-off is imposed by the $0.1 \mathrm{~mm}$ minimum recording definition of the conventional rain gauges. 


\section{Concluding remarks}

The characterization of the scale-invariant structure of precipitation can help to improve our knowledge about this process in the Madeira archipelago. At present there is almost complete lack of studies of local precipitation at small scales, which are the relevant scales in this territory regarding rainfall-induced hydrological processes. The very small size of the drainage basins in these islands, and the very scarce and limited high-resolution monitoring of the precipitation process in the Madeira archipelago are likewise stressed.

This work shows that scale-invariant and multifractal properties are present in the temporal structure of precipitation in the Madeira archipelago; scaling is maintained from at least $10 \mathrm{~min}$ up to about two weeks. This result can contribute to improving the estimation of the statistical properties of precipitation at scales of less than one day by providing a theoretical support for extrapolating properties across scales: from larger scales (that can be investigated using daily data) to smaller scales. This is an important issue because many hydrological studies require knowledge of the statistics of precipitation at shorter time scales (i.e. less than one day) although generally only daily data is available. It is also expected that multifractal theory and its application in models will offer tools to produce high-resolution synthetic precipitation data. The synthetic precipitation data can be used in many hydrological applications and studies (e.g. rainfall-runoff, soil erosion, spread of pollutants, urban drainage), thus mitigating the shortage of historical high resolution data that poses a problem for most conventional statistical approaches to the study of precipitation.

The empirical multifractal exponent functions characterizing the scaling statistical properties of the precipitation intensity were described using a multifractal model based on Lévy random variables which is called universal multifractal model. The results show that the different drivers of precipitation in the islands lead to several precipitation signatures over time. The dynamics of precipitation characterized by the multifractal approach is increasing our understanding of the hydrological regime in the islands. This study gives complementary insight not only into the mean behaviour of rain, which is explored more often, but also into the full dynamical range of the process. It shows that the wetter spots in the northern sector of the Madeira Island and in the central highlands are characterized by less intermittent rain, and that rain there has a higher degree of multifractality.

The data sets used in this work do not provide the uniform spatial coverage of the precipitation distribution over the Madeira Islands which could allow us to fully understand the spatial variability of precipitation over the archipelago. Also the limited continuous records available impede the smallscale characterization of rain in time. Nevertheless, the results stress that the dependency of the multifractality of precipitation on climatological, geographical and even other factors (e.g. precipitation-generating mechanisms, sample size, type of data acquisition) cannot be ignored because these can affect the statistical characteristics of the sample, as it may be expected.

The results of the analyses of the different data sets used in this work suggest and confirm that the different fractal and multifractal descriptions of rain reported in the literature, which are sometimes apparently inconsistent, can probably be explained in terms of the different characteristics of the precipitation data (for example: data resolution, length of the time series, local climate). We refer especially to the different scaling ranges in time and to multifractal parameters that have been reported by various studies (see references given in Sects. 2 and 4). In particular, for orographic precipitation see also e.g. Harris et al. (1996), Purdy et al. (2001), Nykanen and Harris (2003) and Deidda et al. (2006). Two main reasons were identified by Deidda et al. (2006) as contributing to different outcomes in rainfall analyses: a physical factor lies in the different orographic range covered by the data (a limited range may not represent a significant obstacle for perturbations); a second explanation may be the differences in the length of the observation periods (relatively brief observation period may not allow filtering the single events high space-time variability from the possible spatial heterogeneity). These issues need to be further investigated but they stress that in non-homogeneous hydrological regions extrapolation of results to different geographical areas should be considered carefully.

Future work will include a more complete and systematic analysis of precipitation extremes, including the analysis of the probability distributions of precipitation intensities on different scales. The exploration of the available (but limited) data from continuously recording gauges installed in the Madeira archipelago is worth being pursued, too, to allow a firmer definition of the precipitation scaling regimes in the region. This characterization should be correlated with the prevailing weather types for the territory, in order to better understand the extent of the influence of orography on the precipitation observed across the islands.

Acknowledgements. This work was carried out under research projects POCI/GEO/59712/2004 and PTDC/GEO/73114/2006, funded by the Portuguese Foundation for Science and Technology of the Portuguese Ministry of Science, Technology and Higher Education (Lisbon). The authors acknowledge the collaboration in this study of M. F. E. S. Coelho, of the Portuguese Institute of Meteorology, within the framework of the above-mentioned projects.

Edited by: A. Tarquis

Reviewed by: two anonymous referees 


\section{References}

Bendjoudi, H., Hubert, P., Schertzer, D., and Lovejoy, S.: Multifractal point of view on rainfall intensity-duration-frequency curves, C. R. Acad. Sci. II A, 325(5), 323-326, 1997.

Burlando, P. and Rosso, R.: Scaling and multiscaling models of depth-duration-frequency curves for storm precipitation, J. Hydrol., 187(1-2), 45-64, 1996.

Davis, A., Marshak, A., Wiscombe, W., and Cahalan, R.: Multifractal characterizations of nonstationarity and intermittency in geophysical fields: Observed, retrieved, or simulated, J. Geophys. Res., 99(D4), 8055-8072, 1994.

Davis, A., Marshak, A., Wiscombe, W., and Cahalan, R.: Scale Invariance of Liquid Water Distributions in Marine Stratocumulus, Part I: Spectral Properties and Stationarity Issues, J. Atmos. Sci., 53, 1538-1558, 1996.

de Azevedo, E. B., Pereira, L. S., and Bernard Itier, B.: Modelling the local climate in island environments: water balance applications, Agr. Water Manage., 40(2-3), 393-403, 1999.

de Lima, M. I. P.: Multifractals and the temporal structure of rainfall, Ph.D. thesis, Wageningen Agricultural University, The Netherlands, 1998.

de Lima, M. I. P.: A fractal and multifractal study of hourly precipitation time series from the Netherlands, in: Hydrologic Modeling, edited by: Singh, V. P., Seo, I. W., and Sonu, J. H., Water Resources Publications, USA, 15-28, 1999.

de Lima, M. I. P. and Bogardi, J. J.: Multifractals in hydrological studies: the analysis of rainfall time series, in: Proceedings of the UNESCO International Conference Statistical and Bayesian Methods in Hydrological Sciences, UNESCO, Paris, France, 1113 September 1995, Vol. II, 1995.

de Lima, M. I. P. and Grasman, J.: Multifractal analysis of 15-min and daily rainfall from a semi-arid region in Portugal, J. Hydrol., 220, 1-11, 1999.

de Lima, M. I. P., Schertzer, D., Lovejoy, S., and de Lima, J. L. M. P.: Multifractals and the study of extreme precipitation events: a case study from semi-arid and humid regions in Portugal, in: Surface Water Hydrology, edited by: Singh, V. P., Al-Rashid, M., and Sherif, M. M., A. A. Balkema Publishers, Swets \& Zeitlinger B.V., Lisse, The Netherlands, 195-211, 2002.

Deidda, R.: Rainfall downscaling in a space-time multifractal framework, Water Resour. Res., 36(7), 1779-1794, 2000.

Deidda, R., Badas, M. G., and Piga, E.: Space-time multifractality of remotely sensed rainfall fields, J. Hydrol., 322, 2-13, 2006.

Douglas, E. M. and Barros, A. P.: Probable Maximum Precipitation estimation using multifractals: Application in the Eastern United States, J. Hydrometeorol., 4, 1012-1024, 2003.

Falconer, K. J.: Fractal geometry: mathematical foundations and applications, John Wiley \& Sons, Chichester, England, 288 pp., 1990.

Feder, J.: Fractals, Plenum Press, New York, 283 pp., 1988.

Fraedrich, K. and Larnder, C.: Scaling regimes of composite rainfall time series, Tellus, 45A(4), 289-298, 1993.

Frisch, U. and Parisi, G.: Fully developed turbulence and intermittency, in: Turbulence and predicability in geophysical fluid dynamics and climate dynamics, edited by: Ghil, M., Benzi, R., and Parisi, G., Proceedings of the International School of Physics "Enrico Fermi”, Course LXXXVIII, Italian Physical Society, North-Holland, Amsterdam. 1985

Garcia-Herrera, R., Gallego, D., Hernandez, E., Gimeno, L., Rib- era, P., and Calvo, N.: Precipitation trends in the Canary Islands, Int. J. Climatol., 23(2), 235-241, 2003.

Garcia-Herrera, R., Puyol, D. G., Martin, E. H., Presa, L. G., and Rodríguez, P. R.: Influence of the North Atlantic Oscillation on the Canary Islands Precipitation, J. Climate, 14(19), 3889-3903, 2001.

García-Marín, A. P., Jiménez-Hornero, F. J., and Ayuso, J. L.: Applying multifractality and the self-organized criticality theory to describe the temporal rainfall regimes in Andalusia (southern Spain), Hydrol. Process., 22(2), 295-308, 2007.

Grassberger, P.: Generalized dimensions of strange attractors, Phys. Rev. Lett., 97A(6), 227-230, 1983.

Halsey, T. C., Jensen, M. H., Kadanoff, L. P., Procaccia, I., and Shraiman, B. I.: Fractal measures and their singularities: the characterization of strange sets, Phys. Rev. Lett., 33A(2), 11411151, 1986.

Harris, D., Menabde, M., Seed, A., and Austin, G.: Multifractal characterization of rain fields with a strong orographic influence, J. Geophys. Res., 101(D21), 26405-26414, 1996.

Hastings, H. M. and Sugihara, G.: Fractals: a user's guide for the natural sciences, Oxford University Press, Oxford, UK, 235 pp., 1993.

Hentschel, H. G. E. and Procaccia, I.: The infinite number of generalized dimensions of fractals and strange attractors, Physica, 8D, 435-444, 1983.

Hubert, P.: Analyse multifractale de champs temporels d'intensité des précipitations, in: Proceedings of Rencontres hydrologiques FrancoRoumaines, UNESCO, Paris, 3-6 September 1991, SC/92/WS/48, 379-386, 1992.

Hubert, P.: Fractals et multifractals appliqués à l'étude de la variabilité temporelle des précipitations, in: Space and time scale variability and interdependencies in hydrological processes, edited by: Feddes, R. A., Cambridge University Press, UK, 175-181, 1995.

Hubert, P. and Carbonnel, J.-P.: Dimensions fractales de l'occurrence de pluie en climat soudano-sahélien, Hydrologie Continental, 4(1), 3-10, 1989.

Hubert, P. and Carbonnel, J.-P.: Fractal characterization of intertropical precipitations variability and anisotropy, in: Nonlinear variability in Geophysics: scaling and fractals, edited by: Schertzer, D. and Lovejoy, S., Kluwer Academic Publishers, The Netherlands, 209-213, 1991.

Hubert, P., Tessier, Y., Ladoy, P., Lovejoy, S., Schertzer, D., Carbonnel, J. P., Violette, S., Desurosne, I., and Schmitt, F.: Multifractals and extreme rainfall events, Geophys. Res. Lett., 20(10), 931-934, 1993.

Kantelhardt, J. W.: Fractal and multifractal time series, in: Springer encyclopaedia of complexity and system science, Springer, arXiv:0804.0747v1 [physics.data-an], 2008.

Kantelhardt, J. W., Koscielny-Bunde, E., Rybski, D., Braun, P., Bunde, A., and Havlin, S.: Long-term persistence and multifractality of precipitation and river runoff records, J. Geophys. Res., 111, D01106, doi:10.1029/2005JD005881, 2006.

Kiely, G. and Ivanova, K.: Multifractal analysis of hourly precipitation, Phys. Chem. Earth Pt. B, 24(7), 781-786, 1999.

Ladoy, P., Lovejoy, S., and Schertzer, D.: Extreme variability of climatological data: scaling and intermittency, in: Non-linear variability in Geophysics: scaling and fractals, edited by: Schertzer, D. and Lovejoy, S., Kluwer Academic Publishers, The Nether- 
lands, 241-250, 1991.

Ladoy, P., Schmitt, F., Schertzer, D., and Lovejoy, S.: Variabilité temporelle multifractale des observations pluviométriques à Nîmes, C. R. Acad. Sci. II, 317, 775-782, 1993.

Langousis, A. and Veneziano, D.: Intensity-duration-frequency curves from scaling representations of rainfall, Water Resour. Res., 43, W02422, doi:10.1029/2006WR005245, 2007.

Lavallée, D., Schertzer, D., and Lovejoy, S.: On the determination of the codimension function, in: Non-linear variability in Geophysics: scaling and fractals, edited by: Schertzer, D. and Lovejoy, S., Kluwer Academic Publishers, The Netherlands, 99-110, 1991.

Lovejoy, S. and Schertzer, D.: Multifractals, universality classes and satellite and radar measurements of cloud and rain fields, J. Geophys. Res., 95(D3), 2021-2034, 1990.

Lovejoy, S. and Schertzer, D.: Multifractal analysis techniques and the rain and cloud fields from $10^{-3}$ to $10^{6} \mathrm{~m}$, in: Non-linear variability in Geophysics: scaling and fractals, edited by: Schertzer, D. and Lovejoy, S., Kluwer Academic Publishers, The Netherlands, 111-144, 1991.

Lovejoy, S. and Schertzer, D.: Multifractals and rain, in: New Uncertainty Concepts in Hydrology and Water Resources, edited by: Kundzewicz, Z. W., Cambridge University Press - UNESCO International Hydrology Series, New York, 61-103, 1995.

Lovejoy, S. and Schertzer, D.: Scaling and multifractal fields in the solid earth and topography, Nonlin. Processes Geophys., 14, 465-502, 2007, http://www.nonlin-processes-geophys.net/14/465/2007/.

Lovejoy, S., Lilley, M., Desaulniers-Soucy, N., and Schertzer, D.: Large particle number limit in rain, Phys. Rev. E, 68, 025301, doi: 10.1103/PhysRevE.68.025301, 2003.

Mandelbrot, B.: Possible refinement of the lognormal hypothesis concerning the distribution of energy dissipation in intermittent turbulence, in: Statistical Models and Turbulence, Lect. Notes in Phys., 12, 333-351, 1972.

Mandelbrot, B.: Intermittent turbulence in self-similar cascades: divergence of high moments and dimension of the carrier, J. Fluid Mech., 62, 331-358, 1974.

Mandelbrot, B.: Fractals: form, chance and dimension, Freeman, San Francisco, 365 pp., 1977.

Mandelbrot, B.: The fractal geometry of nature, Freeman, San Francisco, 460 pp., 1982.

Marshak, A., Davis, A., Wiscombe, W., and Cahalan, R.: Scale Invariance in Liquid Water Distributions in Marine Stratocumulus. Part II: Multifractal Properties and Intermittency Issues, J. Atmos. Sci., 54(11), 1423-1444, 1997.

Marzol, M. V., Yanes, A., Romero, C., de Azevedo, E. B., Prada, S., and Martins, A.: Caratéristiques des précipitations dans les îles de la Macaronesia (Açores, Madére, Canaries et Cap Vert), in: Proceedings of XIX Colloque de l'Association Internationale de Climatologie, Épernay, France, 415-420, 2006a.

Marzol, M. V., Yanes, A., Romero, C., de Azevedo, E. B., Prada, S., and Martins, A.: Los riesgos de las lluvias torrenciales en las islas de la Macaronesia Azores, Madeira, Canarias Y Cabo Verde, in: Proceedings of V Congresso de la Associación Española de Climatologia "Clima, Sociedad Y Medio Ambiente", Zaragoza, Spain, 443-452, 2006b (in Spanish).

Miranda, P. M. A., Valente, M. A., Tomé, A. R., Trigo, R., Coelho, M. F. E. S., Aguiar, A., and Azevedo, E. B.: O Clima de Portugal nos Séculos XX e XXI, in: Alterações Climáticas em Portugal Cenários, impactos e medidas de adaptação - Projecto SIAM II, edited by: Santos, F. D. and Miranda, P., Gradiva, Portugal, 49113, 2006 (in Portuguese).

Nykanen, D. K. and Harris, D.: Orographic influences on the multiscale statistical properties of precipitation, J. Geophys. Res., 108(D8), 8381-8393, doi:10.1029/2001JD001518, 2003.

Olsson, J., Niemczynowicz, J., Berndtsson, R., and Larson, M.: An analysis of the rainfall time structure by box-counting - some practical applications, J. Hydrol., 137(1-4), 262-277, 1992.

Olsson, J.: Limits and characteristics of the multifractal behaviour of a high-resolution rainfall time series, Nonlin. Processes Geophys., 2, 23-29, 1995, http://www.nonlin-processes-geophys.net/2/23/1995/.

Olsson, J.: Validity and applicability of a scale-independent, multifractal relationship for rainfall, Atmos. Res., 42, 53-65, 1996.

Olsson, J. and Niemczynowicz, J.: Multifractal relations in rainfall data, in: Spatial and temporal variability and interdependencies among hydrological processes, edited by: Kettunen, J., Granlund, K., Paasonen-Kivekäs, M., and Sirviö, H., Proceedings of Nordic Seminar, Kirkkonummi, Finland, 14-16 September 1994, NHP Report No. 36, 110-119, 1994.

Olsson, J. and Niemczynowicz, J.: Multifractal analysis of daily spatial rainfall distributions, J. Hydrol., 187, 29-43, 1996.

Onof, C., Northrop, P., Wheater, H. S., and Isham, V.: Spatiotemporal storm structure and scaling property analysis for modeling, J. Geophys. Res., 101(D21), 26415-26425, 1996.

Pereira, S. C., de Lima, M. I. P., and de Lima, J. L. M. P.: Teste à homogeneidade de séries de precipitação do Arquipélago da Madeira, in: Proceedings of V Congresso Ibérico sobre Gestão e Planeamento da Água, Fundación Nueva Cultura del Agua (FNCA), Escola Superior de Tecnologia, Campus de Gambelas, University of Algarve, Faro, Portugal, 4 to 8 December 2006, 9 pp., 2006 (in Portuguese).

Purdy, J. C., Harris, D., Austin, G. L., Seed, A. W., and Gray, W.: A case study of orographic rainfall processes incorporating multiscaling characterization techniques, J. Geophys. Res., 106(D8), 7837-7845, 2001.

Royer, J.-F., Biaou, A., Chauvin, F., Schertzer, D., and Lovejoy, S.: Multifractal analysis of the evolution of simulated precipitation over France in a climate scenario, C. R. Geosci., 340(7), 431440, 2008.

Schertzer, D. and Lovejoy, S.: Elliptical turbulence in the atmosphere, in: Proceedings of the Fourth Symposium on Turbulent Shear Flows, Karlshule, West Germany, 11.1-11.8, 1983.

Schertzer, D. and Lovejoy, S.: Physical modeling and analysis of rain and clouds by anisotropic scaling multiplicative processes, J. Geophys. Res., 92(D8), 9693-9714, 1987.

Schertzer, D. and Lovejoy, S.: Multifractal simulations and analysis of clouds by multiplicative processes, Atmos. Res., 21, 337-361, 1988.

Schertzer, D. and Lovejoy, S.: Nonlinear geodynamical variability: multiple singularities, universality and observables, in: Nonlinear variability in Geophysics: scaling and fractals, edited by: Schertzer, D. and Lovejoy, S., Kluwer Academic Publishers, The Netherlands, 41-82, 1991.

Sivakumar, B.: Rainfall dynamics at different temporal scales: A chaotic perspective, Hydrol. Earth Syst. Sci., 5, 645-652, 2001, http://www.hydrol-earth-syst-sci.net/5/645/2001/. 
Svensson, C., Olsson, J., and Berndtsson, R.: Multifractal properties of daily rainfall in two different climates, Water Resour. Res., 32(8), 2463-2472, 1996.

Tessier, Y., Lovejoy, S., and Schertzer, D.: Universal multifractals: theory and observations for rain and clouds, in: Proceedings of the 11th International Conference on Clouds and Precipitation, Montreal, Canada, 2, 1098-1101, 1992.

Tessier, Y., Lovejoy, S., and Schertzer, D.: Universal multifractals: theory and observations for rain and clouds, J. Appl. Meteorol., 32(2), 223-250, 1993.

Tessier, Y., Lovejoy, S., Hubert, P., Schertzer, D., and Pecknold, S.: Multifractal analysis and modeling of rainfall and river flows and scaling, causal transfer functions, J. Geophys. Res., 101(D21), 26427-26440, 1996.
Veneziano, D. and Furcolo, P.: Multifractality of rainfall and scaling of intensity-duration-frequency curves, Water Resour. Res., 38(12), 1306-1317, 2002.

Veneziano, D. and Langousis, A.: The areal reduction factor: A multifractal analysis, Water Resour. Res., 41, W07008, doi:10.1029/2004WR003765, 2005.

Veneziano, D., Langousis, A., and Furcolo, P.: Multifractality and rainfall extremes: A review, Water Resour. Res., 42, W06D15, doi:10.1029/2005WR004716, 2006.

Venugopal V., Roux, S. G., Foufoula-Georgiou, E., and Arneodo, A.: Revisiting multifractality of high-resolution temporal rainfall using a wavelet-based formalism, Water Resour. Res., 42, W06D14, doi:10.1029/2005WR004489, 2006. 